\title{
Profile of peptic ulcer disease and its risk factors in Arar, Northern Saudi Arabia
}

Afaf Shuaib Badi Albaqawi ${ }^{1}$, Nagah Mohamed Abo el-Fetoh ${ }^{2}$, Reem Faleh Abdullah Alanazi ${ }^{1}$, Najah Salah Farhan Alanazi ${ }^{1}$, Sara Emad Alrayya ${ }^{1}$, Arwa Nughaymish Mulfi Alanazi ${ }^{1}$, Shoug Zeid Trad Alenezi ${ }^{1}$, Rehab Abdallah Alrkowi Alanazi ${ }^{1}$, Anfal Muaddi Alshalan ${ }^{1}$, Omar Tabaan Alenezi ${ }^{1}$, Wafaa Mohamed Bakr Ali ${ }^{3}$

${ }^{1}$ Intern, Faculty of Medicine, Northern Border University, Arar, Saudi Arabia

${ }^{2}$ Associate Prof. of Public Health and Community Medicine, Faculty of Medicine, Northern Border University, Arar, Saudi Arabia

${ }^{3}$ Student, Faculty of Pharmacy, Sohag University, Sohag, Egypt

\section{Type of article: Original}

\begin{abstract}
Background: Peptic ulcer disease is a multifactorial health problem, and its prevalence and risk factors have changed considerably within the past century.

Objective: To determine the prevalence of peptic ulcer among the population of Arar city and to identify risk factors for peptic ulcer and to estimate their relative impact on ulcer incidence.

Methods: A cross-sectional study was carried out on the population of Arar city, Northern Saudi Arabia from November 01, 2016 to April 30, 2017. Data were analyzed by SPSS version 16, using descriptive statistics, prevalence, and Chi-square test.

Results: Total prevalence of peptic ulcer among the studied respondents was thus: $21.9 \%$ had peptic ulcer; $16.2 \%$ gastric ulcer and $5.6 \%$ duodenal ulcer. In $19.7 \%$ of the cases, the pain was severe, $92.4 \%$ reported that pain was precipitated by certain food. In addition to heartburn, $78.8 \%$ reported loss of appetite, $71.2 \%$ indigestion, $66.7 \%$ regurgitation, $59.1 \%$ nausea and vomiting and $42.4 \%$ with chest pain. Regarding the risk factors, coffee drinking came in first place $(81.8 \%$ ) followed by physical stress in $77.3 \%$, spicy food in $57.6 \%$, prolonged use of Nonsteroidal anti-inflammatory drugs (NSAIDs) in $33.3 \%$ and Helicobacter pylori (H. pylori) infection in $24.2 \%$. A further $22.7 \%$ reported melena as a complication while only $10.6 \%$ reported hematemesis.

Conclusion: This is the first population-based study in Arar, Northern Saudi Arabia reporting point prevalence of peptic ulcer disease. The rate of $16.2 \%$ for gastric ulcer and $5.6 \%$ for duodenal ulcers are substantially high. Coffee drinking, physical stress, spicy food, prolonged use of NSAID and H. pylori infection were the reported risk factors. Population-based endoscopic studies are recommended.

Keywords: Arar; Northern Saudi Arabia; Prevalence; Peptic ulcer; Risk factors
\end{abstract}

\section{Introduction}

Gastric and duodenal ulcers are two kinds of peptic ulcers. The ulcer is a break in the stomach lining, the first part of the small intestine, or sometimes in the lower esophagus. Around $4 \%$ of the population suffer from peptic ulcers (1). There is approximately a $10 \%$ lifetime risk of developing a peptic ulcer (2). Peptic ulcers accounted for 301,000 deaths in 2013, which is down from 327,000 deaths in 1990 (3). Waking at night with upper abdominal pain or upper abdominal pain that escalates with eating are the most common symptoms of duodenal ulcer. With a gastric ulcer, the pain may become worse with eating. Other symptoms are poor appetite, belching, weight loss and vomiting. There are no symptoms in around one third of older people $(1,4,5)$. Studies have revealed that the most common causes are Helicobacter pylori (H. pylori) and Non-steroidal anti-inflammatory drugs (NSAIDs). Other less common causes include cigarette smoking, Behcet's disease, Zollinger-Ellison syndrome, Crohn's disease, stress due to serious illness and liver cirrhosis $(1,6)$. Complications may include bleeding, perforation, and blockage of the

\section{Corresponding author:}

Afaf Shuaib Badi Albaqawi, Faculty of Medicine, Northern Border University, Arar, Saudi Arabia.

Tel.:+966538877759, Email: Afaf_sh93@hotmail.com

Received: August 02, 2017, Accepted: September 19, 2017, Published: November 2017

iThenticate screening: September 19, 2017, English editing: October 15, 2017, Quality control: October 15, 2017

(C) 2017 The Authors. This is an open access article under the terms of the Creative Commons Attribution-NonCommercialNoDerivs License, which permits use and distribution in any medium, provided the original work is properly cited, the use is non-commercial and no modifications or adaptations are made. 
stomach. Bleeding occurs in as many as $15 \%$ of people (7). A study conducted in Iran reported that gastric and duodenal ulcers were identified in 33 (3.26\%) and 50 (4.94\%) participants, making an overall prevalence of $8.20 \%$. Based on multivariable logistic regression analyses, H. pylori infection (OR 3.1, 95\% CI: 2.1-4.7), Smoking (OR: $1.8,95 \%$ CI: 1.1-6.8), and chronic intake of NSAIDs (OR: 2.8) were main risk factors of gastric ulcer. For duodenal ulcer, in addition to H. pylori infection (OR 5.6) and Smoking (OR 2.3), male gender (OR: 3.6) and living in an urban area (OR: 1.9) were among significant risk factors (8). A recent study conducted to identify risk factors for peptic ulcer, reported that the main risk factors were H. pylori infection (odds ratio 4.3), tobac co smoking 3.8 (1.7; 9.8), and use of minor tranquillizers $3.0(1.4 ; 6.6)$. Intake of non-steroid anti-inflammatory drugs did not affect the incidence of peptic ulcer $0.4(0.1 ; 2.3)$. In those with increased antibodies to H. pylori, tobacco smoking $12.7(2.8$; $56.8)$ and intake of spirits $2.4(1.1 ; 5.4)$ increased the risk of PUD whereas moderate leisure time physical activity $0.3(0.2 ; 0.7)$ protected against peptic ulcer $(9)$. The main objective of this study is to identify risk factors for Peptic ulcer and to estimate their relative impact on ulcer incidence and to determine its prevalence among the Saudi population.

\section{Material and Methods}

\subsection{Study design and participants}

A cross-sectional study was carried out on a population of Arar city, Northern Saudi Arabia, KSA during the period from November 01, 2016 to April 30, 2017. We took a representative sample from all the Arar population aged older than 18 years. The sample size was calculated using the sample size equation: $n=z^{2} p(1-p) / e^{2}$. All cases of confirmed diagnosis of peptic ulcer disease were included in the study. Children and young adolescents were excluded. Data was collected from 302 individuals aged between 18 to 75 years. The sampling method we used was systematic random sampling technique from Arar's families, choosing every 10th family. All cases of sure diagnosis of peptic ulcer disease was included in the study.

\subsection{Instrument and data collection}

Data were collected using a pre-designed online questionnaire which included questions designed to fulfill the study objectives. We invited them to participate using a web-based questionnaire. The main researcher sent an invitation message to the participants and asked them to follow a hyperlink to reach and visit a web page where the online questionnaire was published. The questionnaire items were:

1) Socio-demographic characteristics including age, sex, educational level, marital status and occupational status.

2) Questions about abdominal pain, intensity of that pain, if continuous or not, whether it increases with food intake or not and other signs and symptoms of peptic ulcer.

3) The questionnaire also included questions about risk factors like smoking, coffee drinking, spicy food, alcohol and certain types of drugs (NSAID).

4) If the case were diagnosed, how was it diagnosed and what was the diagnosis?

\subsection{Statistical analysis}

All the data were analyzed using SPSS version 16 (SPSS Inc., Chicago, Illinois, USA). Descriptive statistics for the prevalence and quantitative variables and Chi-square test were used. A 2-sided p-value of less than 0.05 was considered statistically significant.

\subsection{Ethical considerations}

Permission to conduct the study was obtained from the Research and Ethics Committee at the College of Medicine, Northern Border University, Arar, Saudi Arabia. Participation in the study was completely voluntary. The questionnaire had a brief introduction (informed consent) explaining the aims and significance of the study. We received the consent to participate in the study by asking the participants to sign it and scan it and send it to the main researcher by email.

\section{Results}

Table 1 shows the socio-demographic characteristics of the participants, Arar, Saudi Arabia. The majority of participants were females $(68.5 \%)$, most were aged between 18 to 25 years, $(57.6 \%)$ were single and $(74.5 \%)$ had high educational level (university). About (34.1\%) were employed. Table 2 illustrates the total prevalence of peptic ulcer among the studied respondents in Arar, Saudi Arabia. It is clear from the table that, $21.9 \%$ had peptic ulcer; $16.2 \%$ gastric ulcer and $5.6 \%$ duodenal ulcer. Table 3 illustrates the characteristics of peptic ulcer among the studied cases. About one fifth (19.7\%) of the cases described the pain as severe, 57.6 as moderate, $36.4 \%$ as continuous and 
http://www.ephysician.ir

$22.7 \%$ as mild pain. Most of the cases $(92.4 \%)$ reported that pain was precipitated by certain food. Regarding signs and symptoms, in addition to heartburn, $78.8 \%$ reported loss of appetite, $71.2 \%$ indigestion, $66.7 \%$ regurgitation, $59.1 \%$ nausea and vomiting and $42.4 \%$ with chest pain. Regarding the risk factors, coffee drinking came in first place $(81.8 \%$ ) followed by physical stress $(77.3 \%)$, spicy food (57.6\%), prolonged use of NSAID (33.3\%) and H. pylori infection (24.2\%). As regards complications, $22.7 \%$ reported melena as a complication while only $10.6 \%$ reported hematemesis. Most of the cases (87.9\%) used antibiotics as treatment and $65.2 \%$ needed hospital admission. Table 4 illustrates the relationship between socio-demographic characteristics and peptic ulcer among the studied population. There is no significant effect of sex, age, educational level or marital status but there was a significant correlation of occupational status $(\mathrm{p}=0.044)$.

Table 1. Socio-demographic characters of the studied population, Arar, Saudi Arabia

\begin{tabular}{|l|l|l|l|}
\hline Variables & Female & $\mathrm{n}($ total=302) & $\%$ \\
\hline \multirow{4}{*}{ Sex } & Male & 207 & 68.5 \\
\hline \multirow{5}{*}{ Age (year) } & $18-25$ & 95 & 31.5 \\
\cline { 2 - 4 } & $26-35$ & 162 & 53.6 \\
\cline { 2 - 4 } & $36-45$ & 84 & 27.8 \\
\cline { 2 - 4 } & $46-55$ & 38 & 12.6 \\
\cline { 2 - 4 } & $55+$ & 12 & 4.0 \\
\hline Educational level & Primary & 6 & 2.0 \\
\cline { 2 - 4 } & Secondary & 65 & 1.7 \\
\cline { 2 - 4 } & University or more & 225 & 21.5 \\
\cline { 2 - 4 } & Preparatory & 7 & 74.5 \\
\hline Marital status & Widow & 2 & 2.3 \\
\cline { 2 - 4 } & Single & 174 & 0.7 \\
\cline { 2 - 4 } & Married & 116 & 37.6 \\
\cline { 2 - 4 } & Divorced & 10 & 3.3 \\
\hline Occupational status & Not employed & 187 & 61.9 \\
\cline { 2 - 4 } & Retired & 12 & 34.1 \\
\cline { 2 - 4 } & Employed & 103 & \\
\hline
\end{tabular}

Table 2. Total prevalence of peptic ulcer among the studied respondents, Arar, Saudi Arabia

\begin{tabular}{|l|l|l|l|}
\hline \multicolumn{2}{|l|}{ Peptic ulcer } & $\mathrm{n}$ & $\%$ \\
\hline \multirow{2}{*}{ Yes $(66,21.9 \%)$} & Gastric ulcer & 49 & 16.2 \\
\cline { 2 - 4 } & Duodenal ulcer & 17 & 5.6 \\
\hline No & 236 & 78.1 \\
\hline Total & 302 & 100.0 \\
\hline
\end{tabular}

Table 3. Characteristics of peptic ulcers among the studied cases, Arar, Saudi Arabia

\begin{tabular}{|c|c|c|c|}
\hline \multicolumn{2}{|l|}{ Characters } & $\mathrm{n}($ total $=66)$ & $\%$ \\
\hline \multirow[t]{6}{*}{ Pain } & Sever & 13 & 19.7 \\
\hline & Mild & 15 & 22.7 \\
\hline & Moderate & 38 & 57.6 \\
\hline & Continues & 24 & 36.4 \\
\hline & Precipitated by certain food & 61 & 92.4 \\
\hline & Decreased after meals & 21 & 31.8 \\
\hline \multirow[t]{8}{*}{ Symptoms and signs } & Nausea and vomiting & 39 & 59.1 \\
\hline & Drowsiness and headache & 25 & 37.9 \\
\hline & Loss of appetite & 52 & 78.8 \\
\hline & Regurgitation & 44 & 66.7 \\
\hline & Associated with sense of gastric erosion & 37 & 56.1 \\
\hline & Loss of weight & 25 & 37.9 \\
\hline & Indigestion & 47 & 71.2 \\
\hline & Chest pain & 28 & 42.4 \\
\hline \multirow[t]{4}{*}{ Risk factors } & Helicobacter pylori infection & 16 & 24.2 \\
\hline & Spicy food & 38 & 57.6 \\
\hline & Smoking & 16 & 24.2 \\
\hline & Alcohol drinking & 4 & 6.1 \\
\hline
\end{tabular}




\begin{tabular}{|c|c|c|c|}
\hline & Psychic stress & 51 & 77.3 \\
\hline & Coffee drinks & 54 & 81.8 \\
\hline & Chronic esophageal disease & 18 & 27.3 \\
\hline & Prolonged use of Non-steroidal anti-inflammatory drugs (NSAID) & 22 & 33.3 \\
\hline & Other drugs & 11 & 16.7 \\
\hline \multirow[t]{2}{*}{ Complications } & Presence of hematemesis & 7 & 10.6 \\
\hline & Presence of melena & 15 & 22.7 \\
\hline \multirow[t]{3}{*}{ Treatment } & Antibiotics & 58 & 87.9 \\
\hline & Responds to antibiotic treatment & 40 & 60.6 \\
\hline & Need hospital admission & 43 & 65.2 \\
\hline \multirow[t]{5}{*}{ Investigated for diagnosis } & Gastroscopy & 17 & 5.6 \\
\hline & Barium meal & 15 & 5.0 \\
\hline & Ultrasound & 20 & 7.0 \\
\hline & Urea breath test & 4 & 1.3 \\
\hline & Others & 10 & 3.3 \\
\hline
\end{tabular}

Table 4. Relationship between peptic ulcers and socio-demographic characters of the studied population, Arar, Saudi Arabia

\begin{tabular}{|c|c|c|c|c|c|c|}
\hline \multirow{2}{*}{\multicolumn{2}{|c|}{ Variables }} & \multicolumn{2}{|l|}{ Peptic ulcer } & \multirow{3}{*}{$\begin{array}{l}\text { Total }(\mathrm{n}=302) \\
207\end{array}$} & \multirow{3}{*}{$\begin{array}{l}\text { Chi-Square } \\
0.279\end{array}$} & \multirow{3}{*}{$\begin{array}{l}p \text {-value } \\
0.356\end{array}$} \\
\hline & & Yes $(n=66)$ & No $(n=236)$ & & & \\
\hline \multirow{4}{*}{ Sex } & \multirow{2}{*}{ Female } & 47 & 160 & & & \\
\hline & & $71.2 \%$ & $67.8 \%$ & $68.5 \%$ & & \\
\hline & \multirow[t]{2}{*}{ Male } & 19 & 76 & 95 & & \\
\hline & & $28.8 \%$ & $32.2 \%$ & $31.5 \%$ & & \\
\hline \multirow[t]{10}{*}{ Age group (year) } & \multirow[t]{2}{*}{$18-25$} & 28 & 134 & 162 & 5.174 & 0.270 \\
\hline & & $42.4 \%$ & $56.8 \%$ & $53.6 \%$ & & \\
\hline & \multirow[t]{2}{*}{$26-35$} & 22 & 62 & 84 & & \\
\hline & & $33.3 \%$ & $26.3 \%$ & $27.8 \%$ & & \\
\hline & \multirow[t]{2}{*}{$36-45$} & 12 & 26 & 38 & & \\
\hline & & $18.2 \%$ & $11.0 \%$ & $12.6 \%$ & & \\
\hline & \multirow[t]{2}{*}{$46-55$} & 3 & 9 & 12 & & \\
\hline & & $4.5 \%$ & $3.8 \%$ & $4.0 \%$ & & \\
\hline & \multirow[t]{2}{*}{$55+$} & 1 & 5 & 6 & & \\
\hline & & $1.5 \%$ & $2.1 \%$ & $2.0 \%$ & & \\
\hline \multirow[t]{8}{*}{ Educational level } & \multirow[t]{2}{*}{ Primary } & 0 & 5 & 5 & 1.924 & 0.588 \\
\hline & & $0.0 \%$ & $2.1 \%$ & $1.7 \%$ & & \\
\hline & \multirow[t]{2}{*}{ Secondary } & 16 & 49 & 65 & & \\
\hline & & $24.2 \%$ & $20.8 \%$ & $21.5 \%$ & & \\
\hline & \multirow[t]{2}{*}{ University + } & 49 & 176 & 225 & & \\
\hline & & $74.2 \%$ & $74.6 \%$ & $74.5 \%$ & & \\
\hline & \multirow[t]{2}{*}{ Preparatory school } & 1 & 6 & 7 & & \\
\hline & & $1.5 \%$ & $2.5 \%$ & $2.3 \%$ & & \\
\hline \multirow[t]{8}{*}{ Marital status } & \multirow[t]{2}{*}{ Widow } & 1 & 1 & 2 & 2.216 & 0.529 \\
\hline & & $1.5 \%$ & $0.4 \%$ & $0.7 \%$ & & \\
\hline & \multirow[t]{2}{*}{ Single } & 34 & 140 & 174 & & \\
\hline & & $51.5 \%$ & $59.3 \%$ & $57.6 \%$ & & \\
\hline & \multirow[t]{2}{*}{ Married } & 28 & 88 & 116 & & \\
\hline & & $42.4 \%$ & $37.3 \%$ & $38.4 \%$ & & \\
\hline & \multirow[t]{2}{*}{ Divorced } & 3 & 7 & 10 & & \\
\hline & & $4.5 \%$ & $3.0 \%$ & $3.3 \%$ & & \\
\hline \multirow[t]{6}{*}{ Working status } & \multirow[t]{2}{*}{ Not employed } & 33 & 154 & 187 & 6.225 & 0.044 \\
\hline & & $50.0 \%$ & $65.3 \%$ & $61.9 \%$ & & \\
\hline & \multirow[t]{2}{*}{ Retired } & 2 & 10 & 12 & & \\
\hline & & $3.0 \%$ & $4.2 \%$ & $4.0 \%$ & & \\
\hline & Employed & 31 & 72 & 103 & & \\
\hline & & $47.0 \%$ & $30.5 \%$ & $34.1 \%$ & & \\
\hline
\end{tabular}




\section{Discussion}

This cross-sectional study included 302 individuals aged between 18 to 75 years old, and aimed to determine the prevalence of peptic ulcer, identify its risk factors and to estimate their relative impact on ulcer incidence. The prevalence of peptic ulcer in our study was $(21.9 \%)$, and $(16.2 \%, 6.2 \%)$ in gastric and duodenal ulcer respectively. However, our findings are higher than findings of European endoscopic epidemiologic studies $(10,11)$ as they reported prevalence rates from $4.1 \%$ (gastric ulcer: $2.0 \%$; duodenal ulcer: $2.1 \%$ ) (11) to $6.2 \%$ (gastric ulcer: $2.3 \%$; duodenal ulcer: 3.9\%) (10). On the other hand, Groenen et al. reported that duodenal ulcers were diagnosed in (3.5\%), gastric ulcers were diagnosed in (2.4\%) (12). Another study conducted in Iran reported that gastric and duodenal ulcers were identified in $33(3.26 \%)$ and $50(4.94 \%)$ of the participants, making an overall prevalence of $8.20 \%$ (8). As Li et al. (13) found in their systematic investigation of gastrointestinal diseases, the prevalence of peptic ulcer in China reaches 17.2\% (gastric ulcer: 6.1\%; duodenal ulcer: $13.3 \%$ ). Another study on a randomly selected population of adults aged 20 years or more, found a point prevalence of (4\%) for peptic ulcer generally (11). Regarding signs and symptoms, (78.8\%) reported loss of appetite, (71.2\%) indigestion, (66.7) regurgitation, (59.1\%) nausea and vomiting, (42.4\%) chest pain, loss of weight and drowsiness, both (37.9\%). A study in the USA found that the most prevalent symptoms among patients with peptic ulcer were abdominal pain (51.4\%), gastroesophageal reflux (40\%), dyspepsia (37.6\%), irritable bowel syndrome $(29.6 \%)$ and epigastric pain $(20.9 \%)$ (11). Another study in the KSA on adolescents and children found that the commonest presentation was chronic abdominal pain in $(63 \%)$ of the participants, followed by vomiting associated with abdominal pain in $(17 \%)$, hematemesis and melena occurred in $(13 \%)$ and $(8 \%)$ respectively (14). Regarding risk factors for peptic ulcer, coffee drinking came in first place $(81.8 \%)$ followed by physical stress $(77.3 \%)$, spicy food $(57.6 \%)$, prolonged use of NSAID (33.3\%) and H. pylori infection (24.2\%). A study in Zambia reported that among cases $(40 \%)$ confirmed history of use of NSAIDs, (57\%) were regular alcohol drinkers and (34\%) were cigarette smokers (15). In the Iranian study (8), results showed that H. pylori infection (2.1\%), smoking (1.1\%) and chronic intake of NSAIDs $(1.3 \%)$ were main risk factors of gastric ulcer. Smoking, aspirin consumption, and obesity were risk factors for $4.1 \%$ prevalence of PUD in northern Sweden (11). Another study of risk factors for peptic ulcer reported (24\%), (48\%) H. pylori and (23\%) cigarette smoking (16). A study in the KSA reported that the overall prevalence rate of $\mathrm{H}$. pylori infection among patients with peptic ulcer was (63\%) (17). Also, a study conducted in Singapore showed that overall $\mathrm{H}$. pylori prevalence was $(67.9 \%)$ in gastric ulcer, $(85.1 \%)$ in duodenal ulcer and $(85.7 \%)$ in combined gastric and duodenal ulcer (18) which are far higher than our figure. While the prevalence of H. pylori infection is low in PUD patients in Denmark (19). The acute clinical complication of ulcers is bleeding. The most common complication for peptic ulcer in this study was melena (22.7\%) followed by hematemesis $(10.6 \%)$. The Saudi study on children and adolescents found that hematemesis and melena occurred in (13\%) and (8\%) respectively (14).

\section{Conclusions}

The rate of $16.2 \%$ for gastric ulcer and 5.6\% for duodenal ulcers in Arar, Northern Saudi Arabia was substantially high. Coffee drinking, physical stress, spicy food, prolonged use of NSAID and Helicobacter pylori infection were the reported risk factors among the studied community. It is strongly suggested; policy makers hold health education campaigns to inform the population regarding the nature of the disease and its risk factors. Population-based endoscopic studies are recommended.

\section{Acknowledgments:}

The success and final outcome of this work required support and assistance of many people and we are fortunate to have got this all along the completion of the work. My thanks go to Hala Mohammed Alanazi (Students, Faculty of Medicine, NBU) for their help in different steps of the research.

\section{Conflict of Interest:}

There is no conflict of interest to be declared.

\section{Authors' contributions:}

All authors contributed to this project and article equally. All authors read and approved the final manuscript.

\section{References:}

1) Najm, WI. Peptic ulcer disease. Primary care. 2011; 38 (3): 383-94. doi: 10.1016/j.pop.2011.05.001. PMID: 21872087.

2) Snowden FM. Emerging and reemerging diseases: a historical perspective. Immunol Rev. 2008; 225(1): 926. doi: 10.1111/j.1600-065X.2008.00677.x. PMID: 18837773. 
3) GBD 2013 Mortality and Causes of Death, Collaborators. Global, regional, and national age-sex specific all-cause and cause-specific mortality for 240 causes of death, 1990-2013: a systematic analysis for the Global Burden of Disease Study 2013. Lancet. 2015; 385(9963): 117-71. doi: 10.1016/S01406736(14)61682-2. PMID: 25530442, PMCID: PMC4340604.

4) Definition and Facts for Peptic Ulcer Disease. National Institute of Diabetes and Digestive and Kidney Diseases. 2015.

5) Rao S. Clinical Manual of Surgery. Elsevier. 2014: 526. ISBN: 9788131238714.

6) Steinberg KP. Stress-related mucosal disease in the critically ill patient: risk factors and strategies to prevent stress-related bleeding in the intensive care unit. Critical Care Medicine. 2002; 30(6 Suppl): S3624. doi: 10.1097/00003246-200206001-00005. PMID: 12072662.

7) Milosavljevic T, Kostić-Milosavljević M, Jovanović I, Krstić M. Complications of peptic ulcer disease. Digestive diseases. 2011; 29(5): 491-3. doi: 10.1159/000331517. PMID: 22095016.

8) Barazandeh F, Yazdanbod A, Pourfarzi F, Sepanlou SG, Derakhshan MH, Malekzadeh R. Epidemiology of Peptic Ulcer Disease: Endoscopic Results of a Systematic Investigation in Iran. Middle East J Dig Dis. 2012; 4(2): 90-6. PMID: 24829640, PMCID: PMC4017685.

9) Rosenstock S, Jørgensen T, Bonnevie O, Andersen L. Risk factors for peptic ulcer disease: a population based prospective cohort study comprising 2416 Danish adults. Gut. 2003; 52(2): 186-93. doi: 10.1136/gut.52.2.186. PMID: 12524398, PMCID: PMC1774958.

10) Zagari RM, Law GR, Fuccio L, Pozzato P, Forman D, Bazzoli F. Dyspeptic symptoms and endoscopic findings in the community: the Loiano-Monghidoro study. Am J Gastroenterol. 2010; 105: 565-71. doi: 10.1038/ajg.2009.706. PMID: 20010920.

11) Aro P1, Storskrubb T, Ronkainen J, Bolling-Sternevald E, Engstrand L, Vieth M, et al. Peptic ulcer disease in a general adult population: the Kalixanda study: a random population-based study. Am J Epidemiol. 2006; 163: 1025-34. doi: 10.1093/aje/kwj129. PMID: 16554343.

12) Groenen MJ, Kuipers EJ, Hansen BE, Th Ouwendijk RJ. Incidence of duodenal ulcers and gastric ulcers in a Western population: Back to where it started. Can J Gastroenterol. 2009; 23(9): 604-8. doi: $10.1155 / 2009 / 181059$.

13) Li Z, Zou D, Ma X, Chen J, Shi X, Gong Y, et al. Epidemiology of peptic ulcer disease: endoscopic results of the systematic investigation of gastrointestinal disease in China. Am J Gastroenterol. 2010; 105: $2570-7$. doi: 10.1038/ajg.2010.324. PMID: 20736940.

14) El Mouzan MI, Abdullah AM. Peptic Ulcer Disease in Children and Adolescents. Journal of Tropical Pediatrics. 2004; 50(6): 328-30. doi: 10.1093/tropej/50.6.328. PMID: 15537716.

15) Sondashi KJ, Odimba BFK, Kelly P. A Cross-sectional Study on Factors Associated With Perforated Peptic Ulcer Disease in Adults Presenting to UTH, Lusaka. Medical Journal of Zambia. 2011; 38(2).

16) Kurata JH, Nogawa AN. Meta-analysis of Risk Factors for Peptic Ulcer: NonsteroidalAntiinflammatory Drugs, Helicobacter pylori, and Smoking. J Clin Gastroenterol. 1997; 24(1): 2-17.

17) Karima TM, Bukhari SZ, Ghais MA, Fatani MI, Hussain WM. Prevalence of Helicobacter pylori infection in patients with peptic ulcer diseases. Saudi Med J. 2006; 27(5): 621-6. PMID: 16680249.

18) $\mathrm{Vu} \mathrm{C}, \mathrm{Ng}$ YY. Prevalence of Helicobacter pylori in peptic ulcer disease in a Singapore hospital. Singapore Med J. 2000; 41(10): 478-81. PMID: 11281437.

19) Andersen LP, Rosenstock SJ, Bonnevie O, Jørgensen T. Seroprevalence of immunoglobulin G, M, and A antibodies to Helicobacter pylori in an unselected Danish population. Am J Epidemiol. 1996; 143: 115764. doi: 10.1093/oxfordjournals.aje.a008694. PMID: 8633606 